\title{
Aspectos Operacionais da Soldagem Subaquática Molhada com Eletrodos Revestidos Inoxidável Austenítico
}

\author{
Frank de Mello Liberato ${ }^{1}$, Paulo J. Modenesi ${ }^{1}$, Alexandre Queiroz Bracarense ${ }^{2}$ \\ 1 Universidade Federal de Minas Gerais - UFMG, Programa de Pós-graduação em Engenharia Metalúrgica, Materiais e Minas, \\ Belo Horizonte, MG, Brasil. \\ 2 Universidade Federal de Minas Gerais - UFMG, Programa de Pós-graduação em Engenharia Mecânica, Belo Horizonte, MG, \\ Brasil.
}

Recebido: 24 Nov., 2017

Aceito: 30 Jul., 2018

E-mails: frankmello5@gmail.com (FML), modenesi@demet.ufmg.br(PJM), bracarense@ufmg.br (AQB)
Resumo: A soldagem subaquática molhada é um processo importante para o reparo de estruturas submersas. Contudo, neste, a soldabilidade dos aços estruturais em geral é limitada pela formação de martensita e a fragilização pelo hidrogênio. Além disto, o processo tende a apresentar problemas operacionais como baixa visibilidade da poça de fusão e instabilidades do arco elétrico. Uma possível alternativa para reduzir alguns dos problemas metalúrgicos da soldagem subaquática com eletrodos de aço carbono seria a sua substituição por metais de adição austeníticos. Buscando subsidiar a aplicação desses eletrodos, o presente trabalho avalia características operacionais da soldagem subaquática molhada com eletrodos revestidos comerciais de três aços inoxidáveis austeníticos e compara os resultados com os da soldagem com um eletrodo de aço carbono e com os da soldagem ao ar. Os testes foram realizados com um sistema mecanizado por gravidade tanto ao ar como no ambiente molhado em três diferentes profundidades, usando três diferentes metais base e nas polaridades direta e inversa. Os modos de transferência foram caracterizados em função do eletrodo, polaridade, ambiente e profundidade com base na análise dos sinais elétricos do processo. Foi observada uma transferência predominantemente globular com ocorrência variável de curtos-circuitos. O uso de índices de estabilidade foi avaliado e a evolução do processo durante o consumo do eletrodo investigado. Mostrou-se que a velocidade de fusão dos eletrodos austeníticos é maior do que a do eletrodo ferrítico, contudo, esta diferença diminui na soldagem subaquática.

Palavras-chave: Estabilidade; Taxa de fusão; Soldagem molhada.

\section{Operational Aspects of Underwater Wet Welding with Austenitic Stainless Steel Coated Electrodes}

\begin{abstract}
Underwater wet welding is an important joining process for the repair of submerged structures. However, in this process, structural steel weldability is impaired by martensite formation and hydrogen embrittlement. Furthermore, underwater wet welding is also characterized by operational difficulties as low weld pool visibility and poor arc stability. An alternative to reduce some metallurgical problems of underwater welding of structural steel could be the use of austenitic filler metals. To provide an initial background for the use of these consumables, the present paper evaluates the operational characteristics of shielded metal arc electrodes of austenitic stainless steel and compares their characteristics with those of low carbon steel electrode in both dry and underwater wet environments. Welding trials were performed in air and wet operation at three different depths, using both current polarities and on three different base metals. Voltage and current signals were analyzed to determined metal transfer mode and process stability indexes were calculated. In all trials, globular metal transfer with variable short-circuit events was observed. Process evolution during electrode melting was studied. It was shown that electrode melting rate of austenitic electrodes was higher than that of the low-carbon electrode. However, this difference was smaller in underwater welding.
\end{abstract}

Key-words: Stability; Fusion rate; Wet welding.

\section{Introdução}

Estruturas "offshore" têm uma importância global na infraestrutura da indústria de óleo e gás. Estas estruturas fornecem suporte estratégico na exploração, produção e transporte de óleo e gás [1]. A manutenção dessas tem sido um grande desafio para 
companhias de operação "offshore". Reparos devem ser feitos em decorrência de danos na estrutura metálica, que podem ocorrer durante ou após sua instalação, por exemplo, devido a problemas de fadiga, corrosão, colisões de navios transportadores e a diversos fenômenos da natureza. Em muitos casos, os metais base desses componentes são aços de alta resistência, com carbono equivalente elevado, o que demanda cuidados adicionais para a sua soldagem.

Uma das técnicas existentes e utilizada no reparo das estruturas "offshore" é a soldagem subaquática molhada com eletrodos revestidos. No caso desse processo de soldagem, o arco elétrico, além de sofrer interferência da pressão ambiente, está em contato direto com a água. Os problemas associados a este método de soldagem são as dificuldades operacionais decorrentes da pouca visibilidade do arco, maior instabilidade do processo, maior tendência à formação de inclusões de escória, trincas, porosidade e as piores propriedades mecânicas obtidas quando comparadas à soldagem atmosférica [2]. Do ponto de vista metalúrgico, a alta velocidade de resfriamento e o elevado teor de hidrogênio absorvido pelo metal fundido são alguns dos principais problemas a serem controlados para evitar a formação de trincas a frio e a baixa tenacidade das juntas soldadas. A soldagem molhada, no entanto, é frequentemente selecionada entre as outras técnicas disponíveis por sua rápida implementação e relativa facilidade para a sua realização reduzindo, portanto, o tempo gasto em relação a outras técnicas. Devido à sua versatilidade e baixo custo, a soldagem molhada é usada há muitos anos como alternativa nos reparos das plataformas e outras estruturas, especialmente em profundidades menores que $60 \mathrm{~m} \mathrm{[1].}$

Durante a soldagem molhada, o metal de base e o metal de adição fundem rapidamente de modo similar ao observado na soldagem ao ar, mas sofrem um resfriamento brusco, decorrente do contato com a água, que promove taxas de resfriamento elevadas. Como resultado deste resfriamento mais rápido e da interação com o ambiente aquático, a solda tende a apresentar microestrutura diferente e uma maior presença de descontinuidades em relação a juntas soldadas obtidas com parâmetros similares na soldagem a seco [3].

O resfriamento da junta na soldagem molhada pode ser dividido em dois regimes: resfriamento mais lento em altas temperaturas, enquanto o material está sob a influência da bolha de gás geralmente formada junto ao arco, e resfriamento acelerado, em temperaturas mais baixas, após o destacamento desta bolha do arco elétrico [4]. A bolha, quando se destaca e sobe em direção à superfície da água, leva consigo uma parcela do calor gerado no processo e leva o metal de solda ainda quente ao contato direto com a água. Além de sua influência metalúrgica, a formação e colapso das bolhas parecem ter um efeito significativo na estabilidade do processo de soldagem e na transferência de metal [5]. Neste sentido, na soldagem subaquática com arame tubular, Feng et al. [5] e Guo et al. [6] observaram que as condições de retenção da bolha de gás junto ao arco e a velocidade de soldagem influenciam significativamente a estabilidade e a transferência de metal.

Fatores adicionais que podem afetar a estabilidade do processo na soldagem molhada incluem, por exemplo, o resfriamento do arco pelo contato com a água, a pressão do ambiente (dependente da profundidade de trabalho), a concentração de hidrogênio nos gases em contato com o arco, o comprimento do arco, a formulação e teor umidade do eletrodo, o tipo, a polaridade e valor da corrente e as características da fonte de soldagem [6-8].

Em soldagem, o termo estabilidade é, em geral, usado de uma forma ampla, podendo estar relacionado com diferentes aspectos do processo e ser caracterizado por diferentes abordagens. Estre estas, pode se citar o aspecto do cordão de solda, a presença ou quantidade de respingos, o uso de parâmetros resultantes da análise dos sinais elétricos do processo, variações de luminosidade, de som ou do volume de fumos e a análise de imagens da região do arco. Todas estas abordagens têm sido exploradas para caracterizar a operação de soldagem em ambiente terrestre com destaque para a análise de sinais elétricos do processo. Em soldagem subaquática molhada, o volume de trabalhos nesta área é menor, havendo um maior foco na busca por formas de mitigar os relevantes problemas metalúrgicos associados com esta operação.

Liu e Guerrero [9] avaliaram eletrodos AWS E6013, E7018 e E7024 em profundidades de 50 e 100, com eletrodo tanto na polaridade negativa como na positiva. Os modos de transferência foram avaliados a partir dos sinais de tensão tanto no domínio do tempo como da frequência. Um índice de estabilidade definido como a razão entre as correntes máxima e mínima medidas foi usado (mais próximo de um, maior a estabilidade). Os resultados, contudo, indicaram que nem sempre o valor deste índice correlaciona bem com as condições de soldagem observadas. Foi observado, também, um desempenho mais estável do eletrodo E6013 com polaridade negativa. 
Oliveira et al. [4] estudaram os mesmos eletrodos a 0,5 $\mathrm{m}$ de profundidade. A estabilidade do processo foi estimada com o valor médio das razões entre as correntes máxima e mínima medidas em intervalos de 10 ms. Filmagem de alta velocidade foi também realizada para caracterizar a formação de bolhas de gás junto ao arco. Não foram observadas diferenças significativas do índice de estabilidade para os diferentes eletrodos, mas foi possível correlacionar características do sinal elétrico com a formação e destacamento das bolhas de gás.

Mazzaferro e Machado [8] avaliaram mudanças nas condições operacionais na soldagem molhada em profundidades de 5 a 20 m com eletrodos contendo quantidades variadas de $\mathrm{CaCO}_{3}$, $\mathrm{TiO}_{2}$ e alumínio. Uma tendência da taxa de deposição $(\mathrm{kg} / \mathrm{h})$ aumentar com a profundidade foi observada. A estabilidade do processo foi caracterizada pelo inverso dos coeficientes de variação (média/desvio padrão) da corrente e tensão de soldagem, por histogramas de tensão, número de curtos-circuitos e de potência relativa entre as frequências de 0 e $10 \mathrm{~Hz}$ calculada a partir de espectogramas da tensão de soldagem. Entre os índices estudados, este último teria permitido uma melhor avaliação do efeito da formulação dos eletrodos e da profundidade na estabilidade do processo. Os autores observaram, em geral, uma melhor estabilidade do processo na maior profundidade, o que atribuíram à constrição do arco pela maior pressão. Com base em resultados de outros trabalhos, contudo, alertam que, em profundidades ainda maiores, a constrição do arco se torna excessiva deteriorando as condições operacionais.

Khan et al. [7] estudaram o desempenho na soldagem molhada de 10 variedades de eletrodos comerciais e concluíram que os rutílicos (com o eletrodo negativo) e oxidantes (nas duas polaridades) apresentam o melhor desempenho operacional avaliado a partir dos oscilogramas de tensão.

Feng et al. [5] estudaram as características operacionais na soldagem molhada com arame tubular e associaram a estabilidade do processo às condições de formação e colapso da bolha de gás. Foram usados, para caracterizar a operação, vídeo de alta velocidade com iluminação de raios-X e a análise dos sinais elétricos do processo, incluindo o coeficiente de variação da tensão, curvas "características dinâmicas" e análise espectral.

Todos os estudos relados foram desenvolvidos com consumíveis de aço carbono ou de baixa liga. Por outro lado, consumíveis de aço inoxidável austenítico têm uma aplicação potencial em algumas aplicações na soldagem subaquática molhada como, por exemplo, no reparo em componentes de reatores nucleares [10] e na manutenção de estruturas da indústria offshore de aços com maior resistência mecânica e teor mais elevado de carbono e outros elementos de liga. Não foi encontrado, contudo, nenhum estudo sistemático de aspectos operacionais de eletrodos austeníticos na soldagem molhada. Neste contexto, o presente trabalho busca apresentar um estudo de aspectos operacionais da soldagem subaquática molhada nas profundidades de 0,5, 10 e 50 m de profundidade com eletrodos revestidos de aço inoxidável austenítico e sua comparação com a soldagem a seco e, também com o eletrodo AWS E6013.

\section{Metodologia}

Foram usados, no presente trabalho, eletrodos de aço carbono (AWS E6013) e de três classes de aço inoxidável austenítico (AWS E309L-17, E312L-17 e E316L-17), todos fornecidos por um fabricante nacional e com diâmetro de $4,0 \mathrm{~mm}$. Antes de seu uso, os eletrodos foram impermeabilizados com verniz vinílico incolor para evitar o contato do revestimento com a água na soldagem subaquática. Três metais base foram usados nos testes: aço carbono ASTM A36 e aço carbono aço AISI 1045, ambos na forma de chapas com 19 mm de espessura e aço inoxidável austenítico AISI 304, na forma de chapa com $6 \mathrm{~mm}$ de espessura. Contudo, como, na avaliação posterior dos resultados não se observou uma diferença significativa nas condições operacionais de soldagem em função do tipo de metal base, no presente trabalho, a diferença entre os metais base não será considerada.

Os corpos de prova de aço carbono para soldagem foram confeccionados com $300 \mathrm{~mm}$ de comprimento e $250 \mathrm{~mm}$ de largura e os de aço inoxidável com o mesmo comprimento e $200 \mathrm{~mm}$ de largura. A oxidação superficial da superfície dos corpos de prova de aço carbono foi removida com disco abrasivo, enquanto que os corpos de prova de aço inoxidável foram apenas desengordurados. Estes últimos foram ponteados em uma base de aço carbono com $19 \mathrm{~mm}$ de espessura para minimizar a sua distorção durante a soldagem.

Foram realizados testes de soldagens (deposição de cordão sobre chapa) de forma mecanizada por gravidade ao ar e debaixo d'água em três profundidades $(0,5 ; 10$ e $50 \mathrm{~m})$. As maiores profundidades foram simuladas em um tanque hiperbárico, enquanto que os testes a $0,5 \mathrm{~m}$ de profundidade foram realizados dentro de um tanque 
aberto, sendo que, em todos os casos, foi usada água potável. Em todas as condições, foram usadas fontes para soldagem com controle eletrônico, sendo que, nos testes feitos dentro do tanque hiperbárico, usou-se uma fonte especialmente projetada para soldagem subaquática. Em todos os casos foi mantido o mesmo ajuste do sistema de soldagem por gravidade (Figura 1) de modo a manter a mesma razão entre o comprimento do cordão de solda depositado e o comprimento correspondente fundido no eletrodo de 0,53 .

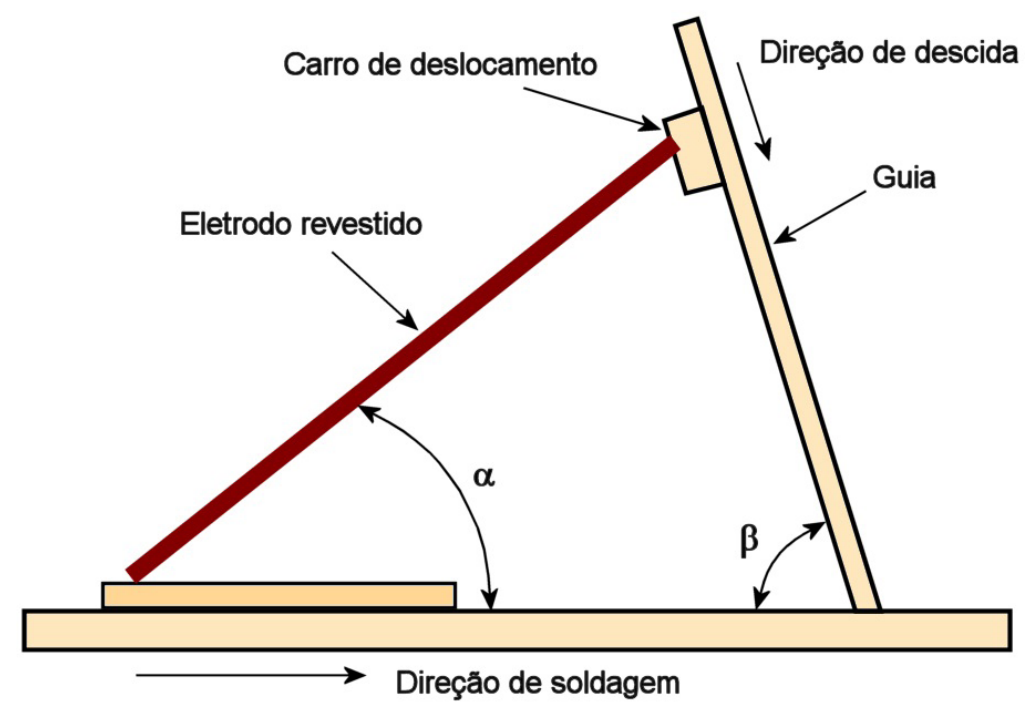

Figura 1. Representação esquemática do sistema de soldagem por gravidade. Os ângulos $\alpha$ e $\beta$ são usados para controlar as condições de deposição da solda.

Todos os testes foram feitos em corrente contínua, mas usando tanto com polaridade direta (CC-) como com inversa ( $C \mathrm{C}+$ ). Nos testes realizados ao ar e em água a 0,5 $\mathrm{m}$ de profundidade, a fonte de soldagem foi ajustada para uma corrente de $160 \mathrm{~A}$; nos testes feitos em água simulando profundidades de 10 e $50 \mathrm{~m}$, ajustou-se uma corrente de $180 \mathrm{~A}$. Estes valores foram baseados em informações do catálogo do fabricante para os eletrodos usados e em resultados de ensaios anteriores realizados no laboratório em soldagem subaquática molhada com o eletrodo de aço carbono. Para cerca de $80 \%$ das condições testadas, foram executados pelo menos três testes de soldagem por condição ensaiada.

Em todos os testes foi feita a monitoração da corrente e tensão de soldagem desde a abertura do arco até a sua extinção usando um sistema digital de aquisição de dados operando a $2 \mathrm{kHz}$. A corrente de soldagem foi medida a partir de um sensor de efeito Hall e a tensão a partir dos bornes das fontes de soldagem com um divisor de tensão. Os arquivos de dados foram processados principalmente com o programa Sinal desenvolvido no laboratório.

O início do intervalo de medição foi selecionado 2 a 4 s após a abertura do arco e o seu final de 1 a $2 \mathrm{~s}$ antes de seu apagamento (Figura 2). Tanto o início como final do intervalo foram escolhidos de forma arbitrária procurando minimizar a influência dos períodos inicial e final de operação em que as condições de soldagem tendem a ser menos estáveis.

Para cada ensaio foram calculados, no intervalo de medição, os valores médios de corrente e tensão de soldagem e os seus desvios padrões, o tempo médio entre os inícios de dois curtos-circuitos consecutivos (T) e a duração média dos curtos-circuitos (tcc). Estes tempos foram calculados usando um algoritmo similar usado por Mazzaferro e Machado [8] e descrito por Modenesi e Avelar [11] baseado na definição de uma tensão de corte para definir a separação entre períodos de arco e de curto (Figura 3). Foi ainda imposta uma condição de rejeição de curtos-circuitos de duração mínima (um único ponto) para minimizar a influência de pequenas flutuações de tensão nos resultados. Com base nos valores de T e tcc, foi calculado o fator de curto-circuito (Fcc) definido como (Equação 1):

$$
F c c=\frac{t_{c c}}{T} \cdot 100
$$




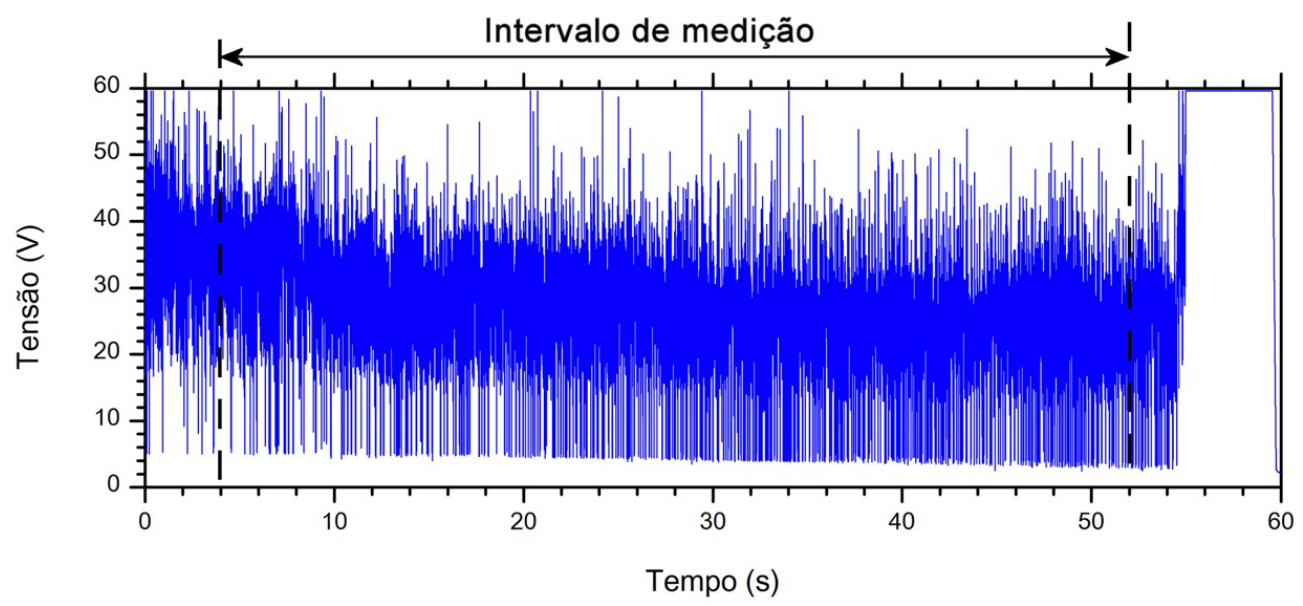

Figura 2. Intervalos de operação com arco e em curto-circuito.

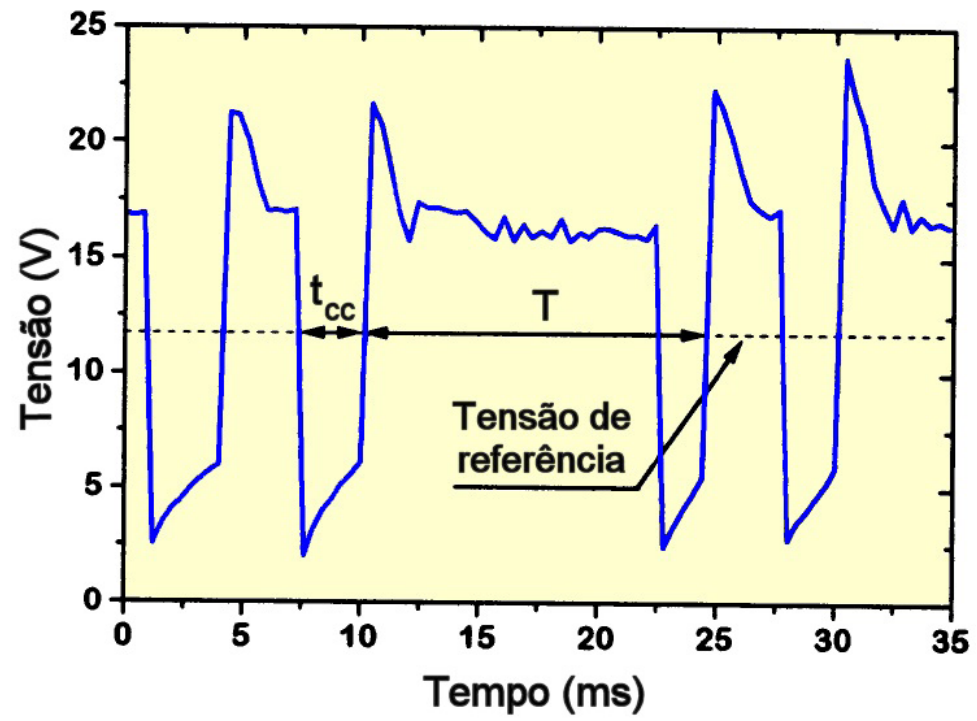

Figura 3. Algoritmo para a determinação dos tempos associados com a transferência por curto-circuito ( $t_{c c}$ ) [11].

Em alguns casos ainda foram calculados a tensão média de operação com arco, definida, em curvas "características dinâmicas" pela média dos valores de tensão superiores a $12 \mathrm{~V}$ (valor definido com base na análise destas curvas (ver a próxima seção) e a resistência do eletrodo (Rcc - definida pelo valor da resistência elétrica média durante os períodos de curto-circuito). O índice de estabilidade (S) usado por Liu e Guerrero [9] foi calculado como o valor médio das razões entre os valores máximo e mínimo da corrente determinadas em subdivisões de 0,1 s de duração do intervalo de medição (Figura 2).

Finalmente, a velocidade de fusão do eletrodo foi calculada medindo-se o comprimento do eletrodo consumido durante o teste e dividindo-o pelo tempo de soldagem.

\section{Resultados e Discussão}

\subsection{Testes a seco}

Por servirem de padrão para a comparação com as condições de soldagem molhada, os resultados dos testes realizados ao ar serão primeiramente apresentados e analisados. As Tabelas 1 e 2 resumem os parâmetros determinados a partir da análise dos sinais elétricos destes testes. Nas duas polaridades, os eletrodos de aço 
Tabela 1. Parâmetros calculados para os testes realizados ao ar com eletrodo negativo (CC-).

\begin{tabular}{|c|c|c|c|c|c|c|c|c|c|c|}
\hline \multirow{2}{*}{ Eletrodo } & \multicolumn{2}{|c|}{ Corrente (A) } & \multicolumn{2}{|c|}{ Tensão (V) } & \multicolumn{2}{|c|}{$\mathbf{T}(\mathbf{s})$} & \multicolumn{2}{|c|}{ Fcc (\%) } & \multicolumn{2}{|c|}{$\operatorname{Rcc}(m \Omega)$} \\
\hline & Média & DP & Média & DP & Média & DP & Média & DP & Média & DP \\
\hline E6013 & 164 & 5 & 21,5 & 1,3 & 0,10 & 0,02 & 5,6 & 0,8 & 18 & 7 \\
\hline E309L & 157 & 0 & 26,5 & 0,5 & 0,26 & 0,01 & 2,4 & 0,5 & 31 & 6 \\
\hline E312L & 167 & 7 & 24,0 & 0,1 & 0,13 & 0,02 & 6,3 & 1,2 & 30 & 7 \\
\hline E316L & 165 & 7 & 28,7 & 0,9 & 0,15 & 0,04 & 2,7 & 0,8 & 33 & 8 \\
\hline
\end{tabular}

$\mathrm{DP}=$ Desvio padrão; $\mathrm{T}=$ Tempo médio entre o início de curtos; Fcc = Fator de curto-circuito; Rcc = Resistência elétrica durante os curtos.

Tabela 2. Parâmetros calculados para os testes realizados ao ar com eletrodo positivo (CC+).

\begin{tabular}{|c|c|c|c|c|c|c|c|c|c|c|}
\hline \multirow{2}{*}{ Eletrodo } & \multicolumn{2}{|c|}{ Corrente (A) } & \multicolumn{2}{|c|}{ Tensão (V) } & \multicolumn{2}{|c|}{$\mathbf{T}(\mathbf{s})$} & \multicolumn{2}{|c|}{ Fcc (\%) } & \multicolumn{2}{|c|}{$\operatorname{Rcc}(m \Omega)$} \\
\hline & Média & DP & Média & DP & Média & DP & Média & DP & Média & DP \\
\hline E6013 & 162 & 2 & 20,5 & 0,4 & 0,09 & 0,02 & 6,7 & 0,4 & 18 & 7 \\
\hline E309L & 157 & 1 & 27,7 & 0,8 & 0,70 & 0,08 & 0,9 & 0,2 & 31 & 6 \\
\hline E312L & 171 & 2 & 23,7 & 0,6 & 0,24 & 0,03 & 5,6 & 1,4 & 30 & 7 \\
\hline E316L & 165 & 7 & 26,8 & 0,8 & 0,35 & 0,09 & 2,5 & 0,9 & 32 & 7 \\
\hline
\end{tabular}

DP = Desvio padrão; T = Tempo médio entre o início de curtos; Fcc = Fator de curto-circuito; Rcc = Resistência elétrica durante os curtos.

inoxidável operam com uma tensão aproximadamente $5 \mathrm{~V}$ acima da tensão média de operação do eletrodo de aço carbono, o que, em parte, pode ser atribuído à menor resistividade elétrica deste para temperaturas de até aproximadamente $800{ }^{\circ} \mathrm{C}$. Entre os eletrodos austeníticos, o E312L é o que opera em uma tensão menor (aproximadamente $2 \mathrm{~V}$ maior que a do eletrodo ferrítico).

Entre os eletrodos austeníticos, existe uma relação inversa entre a tensão de operação e o fator de curto-circuito, por exemplo, nas duas polaridades, o eletrodo E312L é o que opera com menor tensão e apresenta mais curtos-circuitos e menores tempos de transferência (T). A resistência elétrica medida nos períodos de curto-circuito (Rcc) dos três eletrodos austeníticos foi similar e aproximadamente $70 \%$ maior que a obtida com o eletrodo E6013. Embora a resistividade elétrica a temperatura ambiente de um aço inoxidável austenítico seja cerca de 5 maior que a de um aço de baixo carbono, esta última aumenta mais rapidamente com a temperatura, tendendo a se aproximar da resistividade do aço inoxidável em torno de $800^{\circ} \mathrm{C}$. Como os eletrodos se aquecem durante a soldagem, pode-se esperar que as diferenças nas resistências de curto-circuito não sejam tão elevadas quanto à das resistividades à temperatura ambiente. Ainda assim, estas diferenças indicam uma maior capacidade de geração de calor por efeito Joule pelos eletrodos austeníticos, o que terá um efeito direto em sua velocidade de fusão em relação ao eletrodo E6013 (ver seção 3.3).

Não se observou uma diferença sistemática nas condições de soldagem em função da polaridade, embora, segundo seu fabricante, os eletrodos austeníticos sejam indicados para soldagem com CC+. Nas duas polaridades, todos os eletrodos apresentam uma transferência mista globular e por curto-circuito. A transferência por curto-circuito foi menos observada nos testes com o eletrodo E309L em CC+ e foi encontrada mais fortemente, em ambas as polaridades, com os eletrodos E6013 e E312L. A maior ocorrência de curtos-circuitos com este último sugere operação com um comprimento de arco menor em comparação com os outros eletrodos inoxidáveis. Na soldagem por gravidade, o comprimento do arco é controlado em grande parte pelo cone de revestimento não fundido à frente da alma metálica, o que, em grande parte, está relacionado com os componentes do revestimento, o que não foi investigada no presente trabalho.

Os valores de Rcc dos eletrodos de aço inoxidável foram similares e, em todos casos, independentes da polaridade. Como a resistência elétrica depende da temperatura do condutor, esse resultado sugere que a distribuição de temperatura e o aquecimento dos eletrodos durante a soldagem não dependa da polaridade, 0 que é razoável uma vez que o aquecimento do eletrodo ocorre por efeito Joule (que não depende da polaridade) e pelo arco elétrico, cuja ação fica restrita a uma pequena região próxima da ponta do eletrodo [12]. 


\subsection{Soldagem molhada e comparação com testes a seco}

As Tabelas 3 e 4 apresentam os valores médios de corrente e tensão de soldagem, nas diferentes condições e profundidades, para os testes com eletrodo positivo e negativo respectivamente. Os valores de corrente ficaram dentro do esperado considerando os ajustes das fontes e a atuação dos sistemas contra a colagem do eletrodo na poça de fusão durante os curtos-circuitos (Figura 4). Também na soldagem molhada, os valores de tensão tenderam a ser menores nos testes com o eletrodo E6013.

Tabela 3. Valores de corrente e tensão médias de soldagem nos testes com eletrodo positivo.

\begin{tabular}{|c|c|c|c|c|c|c|c|c|}
\hline \multirow{3}{*}{$\begin{array}{l}\text { Profundidade } \\
\text { (m) }\end{array}$} & \multicolumn{4}{|c|}{ Eletrodos de aço inoxidável } & \multicolumn{4}{|c|}{ Eletrodo de aço carbono } \\
\hline & \multicolumn{2}{|c|}{ Corrente (A) } & \multicolumn{2}{|c|}{ Tensão (V) } & \multicolumn{2}{|c|}{ Corrente (A) } & \multicolumn{2}{|c|}{ Tensão (V) } \\
\hline & Média & Desvio* & Média & Desvio* & Média & Desvio* & Média & Desvio* \\
\hline $\mathrm{Ar}$ & 165 & 6 & 25,2 & 0,9 & 162 & 2 & 20,5 & 0,4 \\
\hline 0,5 & 167 & 2 & 29,6 & 1,3 & 166 & 1 & 27,7 & 3,4 \\
\hline 10 & 190 & 12 & 33,0 & 1,4 & 185 & 11 & 24,7 & 2,0 \\
\hline 50 & 186 & 3 & 29,5 & 1,1 & 182 & 1 & 28,8 & 0,5 \\
\hline
\end{tabular}

*Desvios padrões dos valores médios obtidos em cada ensaio.

Tabela 4. Valores de corrente e tensão médias de soldagem nos testes com eletrodo negativo.

\begin{tabular}{|c|c|c|c|c|c|c|c|c|}
\hline \multirow{3}{*}{$\begin{array}{l}\text { Profundidade } \\
\text { (m) }\end{array}$} & \multicolumn{4}{|c|}{ Eletrodos de aço inoxidável } & \multicolumn{4}{|c|}{ Eletrodo de aço carbono } \\
\hline & \multicolumn{2}{|c|}{ Corrente (A) } & \multicolumn{2}{|c|}{ Tensão (V) } & \multicolumn{2}{|c|}{ Corrente (A) } & \multicolumn{2}{|c|}{ Tensão (V) } \\
\hline & Média & Desvio* & Média & Desvio* & Média & Desvio* & Média & Desvio* \\
\hline $\operatorname{Ar}$ & 163 & 7 & 26,4 & 0,7 & 164 & 5 & 21,5 & 1,3 \\
\hline 0,5 & 169 & 2 & 31,5 & 4,0 & 167 & 2 & 31,0 & 4,3 \\
\hline 10 & 185 & 9 & 28,9 & 1,0 & 186 & 9 & 21,4 & 1,0 \\
\hline 50 & 187 & 4 & 25,1 & 0,8 & 190 & 5 & 21,1 & 2,0 \\
\hline
\end{tabular}

*Desvios padrões dos valores médios obtidos em cada ensaio.

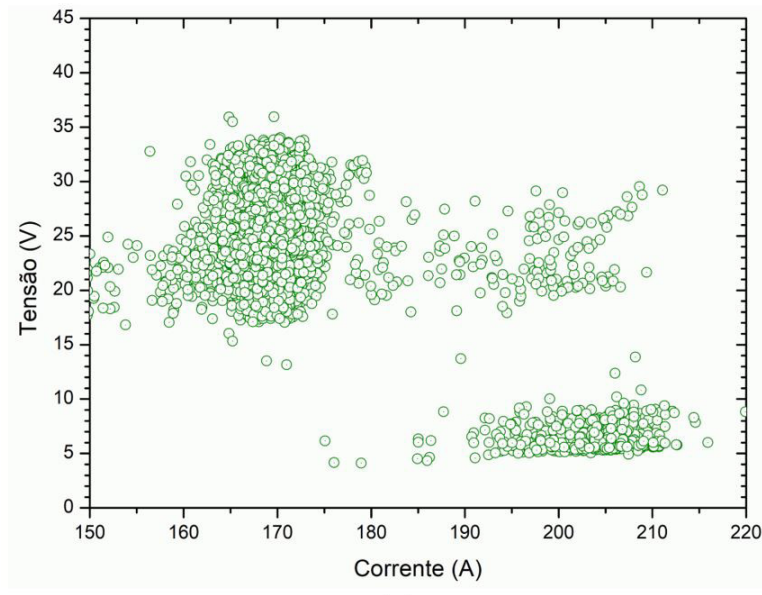

(a)

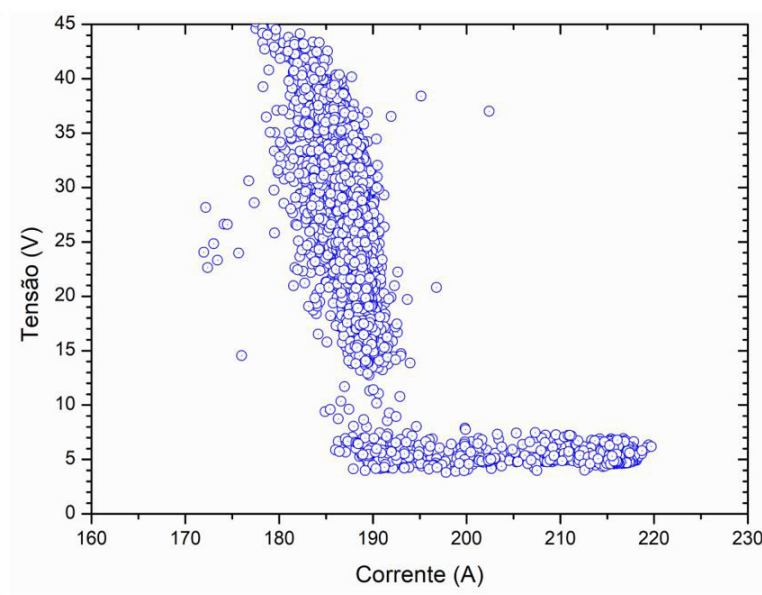

(b)

Figura 4. Curvas características dinâmicas de testes de soldagem com eletrodo E312L ao (a) ar e a (b) 50 m.

A fonte usada nos testes no vaso pressurizado apresentava recurso similar à usada nos testes a seco que aumenta a corrente durante curtos-circuitos. Contudo, como foram usadas fontes diferentes e os sinais apresentavam níveis de ruído diferentes em função fonte usada (Figura 5), não foi feita uma comparação de valores de desvio 


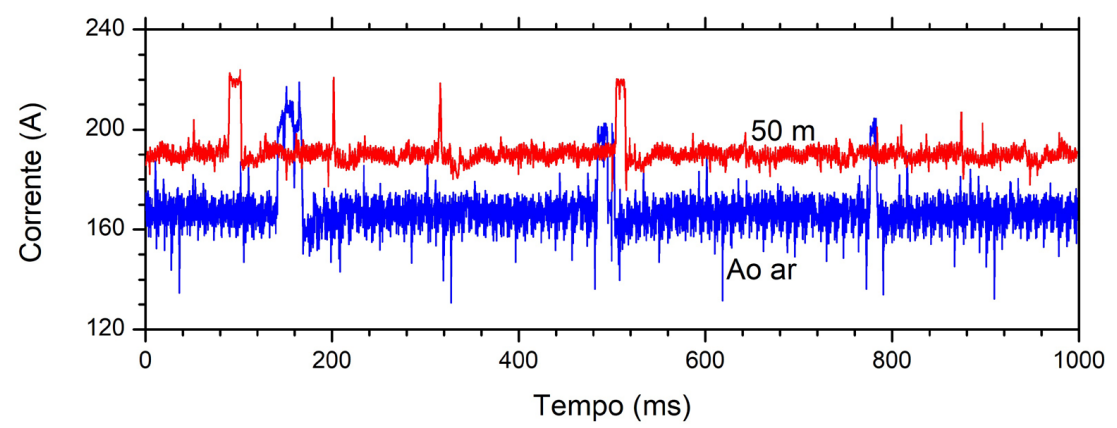

Figura 5. Oscilogramas de corrente de testes realizados ao ar e a $50 \mathrm{~m}$ com o eletrodo E6013 com CC-.

padrão da corrente e tensão entre testes feitos nas diferentes condições e profundidades. A Figura 4 mostra curvas "características dinâmicas" de testes feitos com as duas fontes. O aumento de corrente quando a tensão atingia valores baixos para prevenir a colagem do eletrodo durante curtos-circuitos pode ser vista nos dois casos, juntamente com uma maior dispersão da corrente de soldagem (maior largura da faixa de valores desta na operação em arco) no caso da fonte usada para soldagem fora do vaso de pressão.

A presença e intensidade de curtos-circuitos variou, na soldagem molhada, principalmente com a profundidade, tipo de eletrodo (Figuras 6 e 7) e polaridade. Como na soldagem a seco, os testes com o eletrodo de aço carbono e com o eletrodo inoxidável E312L tenderam a apresentar maior quantidade de curtos-circuitos, exceto para a profundidade de $50 \mathrm{~m}$.

A Figura 8 mostra a evolução da tensão média de soldagem e do fator de curto com a profundidade e a polaridade expressos em valores relativos àqueles obtidos nos testes de soldagem a seco (Tabelas 1 e 2). 0 uso de valores relativos permite mostrar que os parâmetros associados com a soldagem com os eletrodos austeníticos variam de forma similar apesar das diferenças dos valores individuais desses parâmetros.

Na soldagem com os eletrodos de aço inoxidável na polaridade negativa (Figuras 8a e 8c), a tensão de operação é máxima e o fator de curto circuito é mínimo na soldagem em lâmina d’água $(0,5 \mathrm{~m})$. A tensão de soldagem diminui com a profundidade atingindo, a $50 \mathrm{~m}$, valores similares ou inferiores aos encontrados na soldagem ao ar. A presença
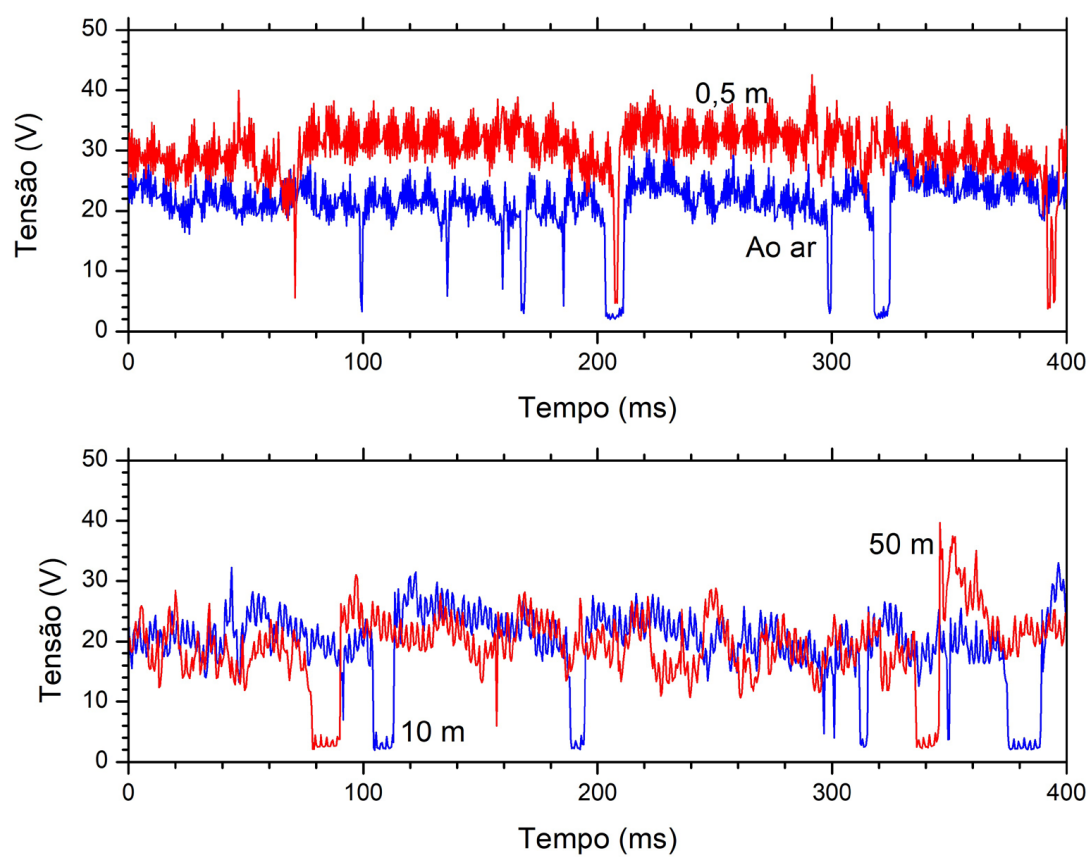

Figura 6. Oscilogramas de tensão de testes realizados nas diferentes profundidades com CC- e eletrodo E6013. 

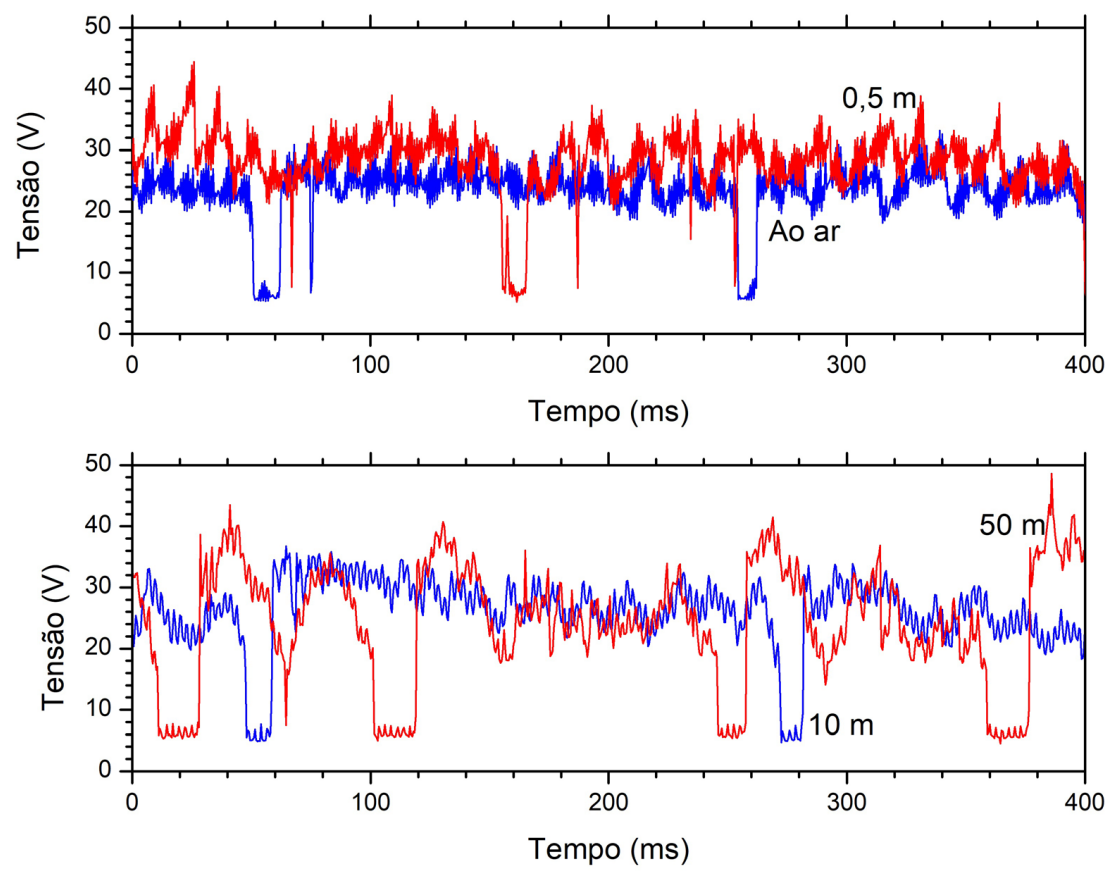

Figura 7. Oscilogramas de tensão de testes realizados nas diferentes profundidades com CC- e eletrodo E312L.

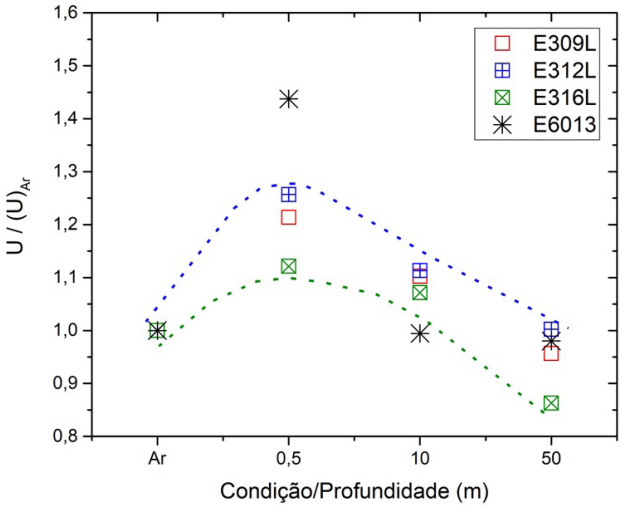

(a)

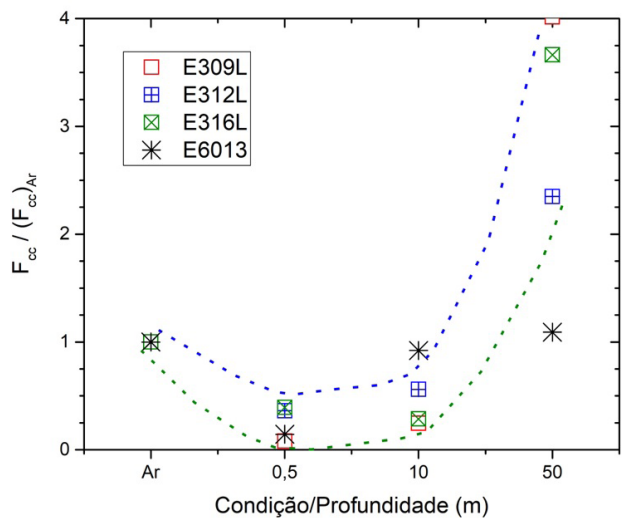

(c)

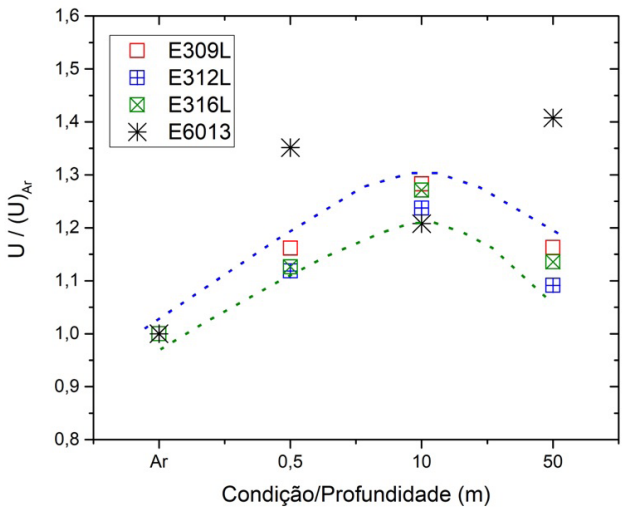

(b)

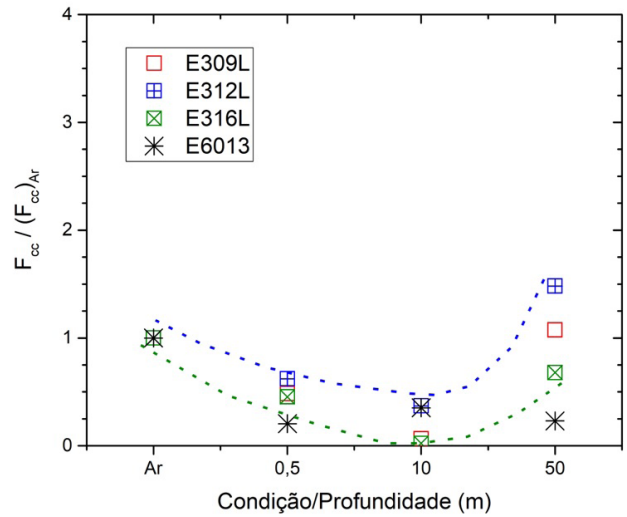

(d)

Figura 8. Variação relativa à soldagem ao ar da tensão média de soldagem com (a) CC- e (b) CC+ e do fator de curto circuito com (c) CC- e (d) CC+. As linhas pontilhadas delimitam aproximadamente a variação dos valores nos testes com os eletrodos austeníticos. 
de curtos-circuitos aumenta com a profundidade, particularmente nos testes com os eletrodos E309 e E312 que apresentam baixa quantidade de curtos-circuitos na soldagem ao ar. Na soldagem com eletrodo positivo, os resultados com os eletrodos inoxidáveis foram similares aos apresentados para CC- com a exceção de que o máximo na tensão e o mínimo em Fcc ocorrem na profundidade de $10 \mathrm{~m}$ e que o aumento de Fcc com a profundidade foi menos intenso.

Na soldagem com eletrodo E6013, na polaridade negativa, a tensão de operação e a intensidade de curtos-circuitos nas profundidades de 10 e $50 \mathrm{~m}$ tiveram valores similares aos da soldagem ao ar. Com eletrodo positivo, a quantidade de curtos-circuitos cai na soldagem molhada e a tensão de operação aumenta em aproximadamente $30 \%$. Estas diferenças de comportamento indicam que a soldagem com eletrodo negativo tem características mais similares à soldagem a seco, o que pode justificar a preferência por esta polaridade na soldagem molhada com estes eletrodos.

Em resumo, observou-se que, embora apresentando valores diferentes de tensão média e de Fcc na soldagem ao ar, os eletrodos de aço inoxidável apresentaram variações de comportamento similares em função da profundidade e da polaridade na soldagem molhada. $O$ forte aumento do fator de curto-circuito com eletrodo negativo para a profundidade de $50 \mathrm{~m}$, sugere que, para profundidades superiores a $10 \mathrm{~m}$, a polaridade positiva deve ser preferida diferentemente do normalmente sugerido na soldagem subaquática com eletrodos rutílicos.

\subsection{Avaliação da estabilidade do processo}

Segundo Omajene et al. [13], a constrição do arco pela pressão ambiente é um fator que afeta de forma importante a estabilidade da soldagem molhada em função da profundidade. Segundo estes, para profundidades até cerca de 1,5 a $6 \mathrm{~m}$, a operação tende a se tornar mais estável com a profundidade, mas, além deste limite, o comportamento é alterado e o processo tende a se tornar mais instável com o aumento da profundidade e a necessitar de uma maior tensão de operação. No presente trabalho, observações qualitativas feitas durante os ensaios indicaram, principalmente com os eletrodos inoxidáveis, uma maior instabilidade do processo, com uma maior tendência à extinção do arco e colagem do eletrodo nos testes realizados a maior profundidade, particularmente a $50 \mathrm{~m}$. Por outro lado, a variação da tensão de soldagem foi diferente da indicada por Omajene, tendendo a diminuir com a profundidade, particularmente na soldagem com CC- (Figuras 8a e 8b). Este comportamento parece estar, pelo menos em parte, associado com a variação da ocorrência de curtos-circuitos durante o processo (Figuras 8c e 8d).

A Tabela 5 mostra a variação do fator de curto-circuito ( $\mathrm{Fcc}$ ) e de alguns parâmetros que são usualmente citados para inferir a estabilidade na soldagem a arco: o desvio padrão da corrente (DP(I)), o desvio padrão da tensão $(D P(U))$ e a razão entre as correntes máxima e mínima medidas (S) em intervalos de tempo de 0,1 s.

O fator de curto-circuito indica a participação relativa dos curto-circuito no processo. Curtos-circuitos são usuais na soldagem com eletrodos revestidos e, desde que a sua participação não seja muito grande ou os eventos não sejam irregulares, não necessariamente indicam baixa estabilidade do processo.

Tabela 5. Valores de alguns parâmetros para caracterizar a estabilidade do processo aplicado em testes com eletrodo negativo.

\begin{tabular}{cccccc}
\hline \multirow{2}{*}{ Eletrodo } & Condição / Prof. (m) & \multicolumn{4}{c}{ P A R Â M E T O S } \\
\cline { 3 - 6 } E6013 & Frc & $\begin{array}{c}\text { DP(I) } \\
\text { (A) }\end{array}$ & $\begin{array}{c}\text { DP(U) } \\
\text { (V) }\end{array}$ & S \\
& $\mathrm{Ar}$ & 5,6 & 17 & 5,1 & 1,65 \\
& 0,5 & 0,8 & 7 & 4,8 & 1,35 \\
& 10 & 5,2 & 5 & 5,8 & 1,13 \\
E309L & 50 & 6,1 & 7 & 6,4 & 1,20 \\
& $\mathrm{Ar}$ & 2,4 & 8 & 5,5 & 1,45 \\
& 0,5 & 0,2 & 6 & 7,4 & 1,20 \\
\multirow{3}{*}{ E312L } & 10 & 0,6 & 3 & 5,3 & 1,09 \\
& 50 & 9,7 & 8 & 8,9 & 1,17 \\
& $\mathrm{Ar}$ & 6,3 & 11 & 5,8 & 1,43 \\
& 0,5 & 2,3 & 6 & 5,3 & 1,27 \\
& 10 & 3,5 & 3 & 6,1 & 1,14 \\
\hline
\end{tabular}

Fcc = Fator de curto-circuito; DP(I) = Desvio padrão da corrente; DP(U) = Desvio padrão da tensão; S = Razão entre as correntes máxima e mínima. 
$\mathrm{DP}(\mathrm{I})$ e DP(U) indicam a variabilidade do processo medida através da corrente ou a tensão de soldagem e um maior valor destes é usualmente associado com uma menor estabilidade na soldagem a seco. Variações de corrente e tensão decorrem de vários fatores incluindo o modo de transferência e as características da fonte de soldagem. No presente trabalho, as fontes usadas elevam a corrente durante curtos-circuitos e apresentam diferentes níveis de ruído que podem contribuir para aumentar a variabilidade dos sinais.

O último parâmetro (S) caracteriza a flutuação de corrente em subintervalos do intervalo de medida, apresentando valores maiores ou iguais a um, sendo que os valores mais elevados são associados com menor estabilidade. Contudo, Liu e Guerrero [9] colocam que, nem sempre, um valor elevado de S coincide com uma maior instabilidade do processo quando esta é inferida pela observação direta do processo.

No presente trabalho, os quatro parâmetros mostrados na Tabela 5 tendem a apresentar valores maiores nas condições extremas, isto é, na soldagem ao ar e na profundidade de $50 \mathrm{~m}$. O resultado associado com a soldagem ao ar não coincide com o esperado e com o que foi observado qualitativamente em termos de estabilidade do processo durante os testes. Por exemplo, apagamento e interrupção do processo de soldagem foram observados mais comumente nos testes com maior profundidade, particularmente a $50 \mathrm{~m}$ e não foram comuns na soldagem ao ar. Estes eventos foram, também, mais comuns na soldagem com os eletrodos inoxidáveis, principalmente o E312L e E316L, e na polaridade positiva. Além disto, como esperado, os eletrodos funcionaram de forma mais estável na soldagem ao ar. Esta dissociação entre o comportamento observado durante a soldagem e valores obtidos de alguns parâmetros usados para caracterizar a estabilidade do processo coincide com o observado por Liu e Guerrero [9]. De fato, as variações de DP(I), DP(U) e S parecem estar mais associadas com o modo de transferência, particularmente com a ocorrência de transferência por curto-circuito (caracterizada pelo valor de Fcc).

Uma abordagem alternativa foi avaliar a evolução destes parâmetros durante a soldagem uma vez que eventos como interrupções do processo e variações explosivas de parâmetros tendem a ocorrer de forma discreta. A Figura 9 ilustra esta abordagem para testes com o eletrodo negativo. Neste exemplo, o fator de curto-circuito foi calculado
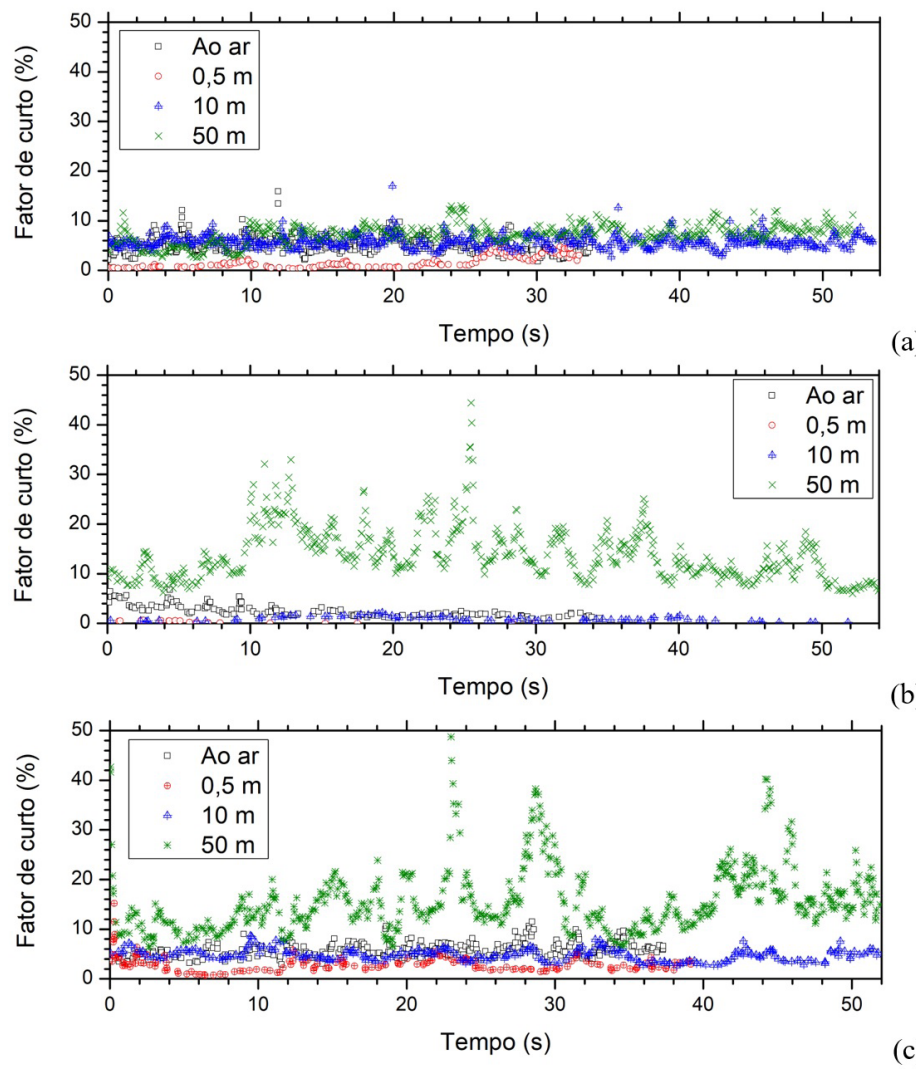

Figura 9. Variação do fator de curto-circuito para testes a diferentes profundidades com eletrodos (a) E6013, (b) E309L e (c) E312L. Operação em CC-. 
em blocos de englobando 7 eventos seguidos de curto-circuito de modo a se obter uma medida relativamente instantânea de Fcc, mas que reduzisse a forte componente aleatória da ocorrência destes eventos. Observa-se que, para os eletrodos inoxidáveis, na maior profundidade $(50 \mathrm{~m})$, o fator de curto-circuito tende a apresentar valores mais elevados e estes sofrem fortes oscilações, atingindo momentaneamente valores próximos a $50 \%$. Este comportamento sugere que a reabertura do arco após a ocorrência de curtos-circuitos é difícil, sugerindo uma pior estabilidade nesta profundidade em linha com o colocado com Omajene et al. [13] e Liu e Guerrero [9].

A Figura 10 mostra resultados com a mesma abordagem para o desvio padrão da corrente (normalizado como o coeficiente de variação). Como no caso anterior, a evolução deste parâmetro sugere uma mudança de comportamento em algumas das condições estudadas. Na maior profundidade e, para o eletrodo E312L a $50 \mathrm{~m}$ de profundidade, este índice muda de valor após cerca de $20 \mathrm{~s}$ de soldagem. Nos testes com o eletrodo E6013, um comportamento semelhante não é observado. Com este eletrodo, o processo apresenta, em algumas condições, uma dispersão elevada dos valores do coeficiente de variação, mas uniformemente distribuída durante a soldagem. $O$ aumento do coeficiente de variação foi associado à ocorrência de picos de corrente fornecidos pelas fontes usadas devido à ocorrência de curtos-circuitos (Figura 5). Assim, nas condições indicadas, à medida que o eletrodo foi consumido, as condições de soldagem mudaram com curtos-circuitos se tornando mais frequentes. As razões deste comportamento não foram levantadas neste trabalho e não foram encontradas referências na literatura a fenômenos similares. $O$ aumento da quantidade de curtos-circuitos nas profundidades de 10 e $50 \mathrm{~m}$, pode estar ligado à demanda por uma maior tensão para a operação do arco devido ao efeito da pressão como indicado por Omajene et al. [13]. Contudo, a razão para este efeito se tornar mais forte algum tempo após o início da soldagem não foi levantada.
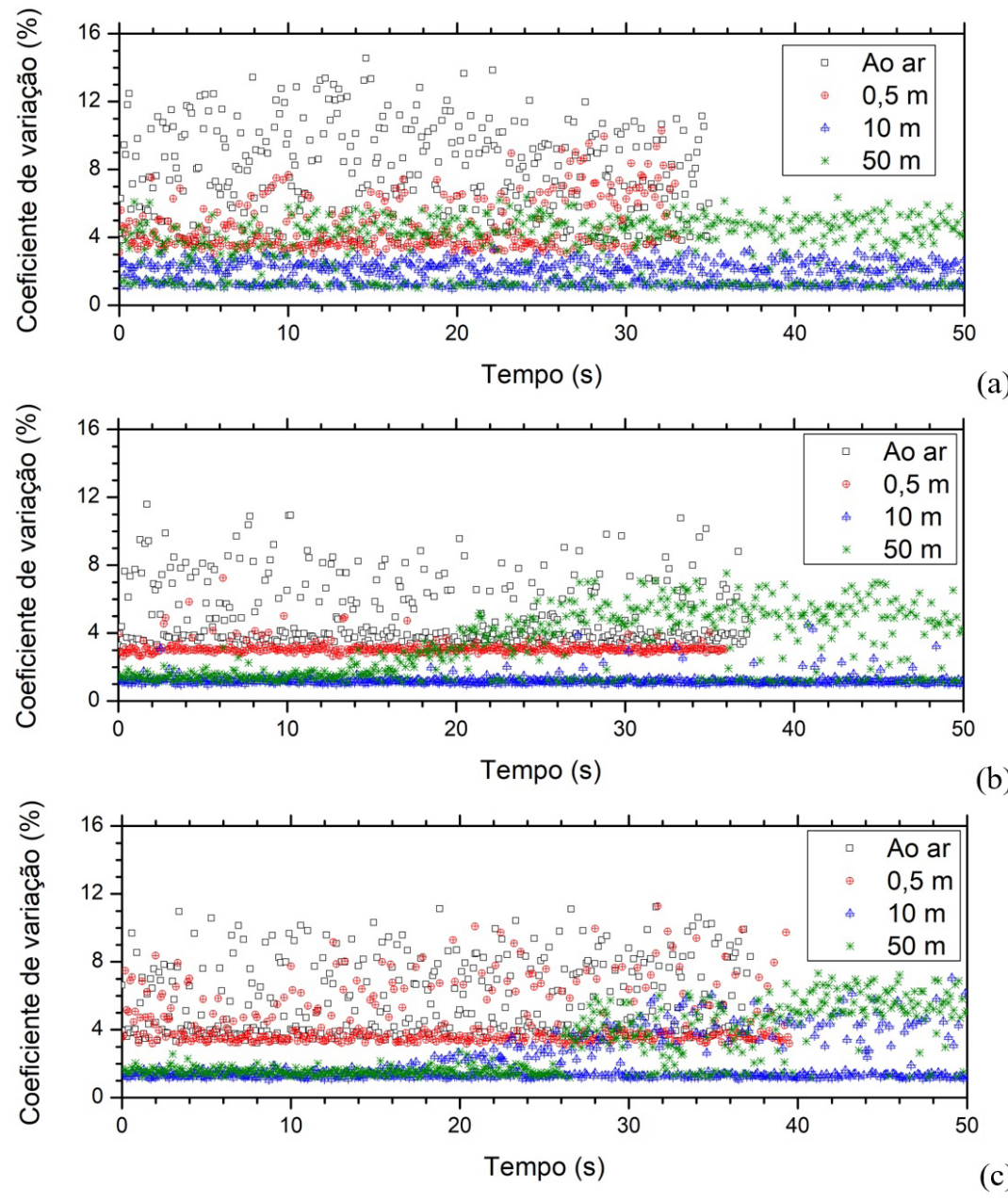

Figura 10. Evolução da razão entre as correntes máxima e mínima em intervalos de $0,1 \mathrm{~s}$ para testes a diferentes profundidades com os eletrodos (a) E6013, (b) E309L e (c) E312L. Operação em CC-. 


\subsection{Velocidade de fusão dos eletrodos}

A Tabela 6 mostra que, na soldagem ao ar, a velocidade de fusão do eletrodo E6013 é menor do a dos eletrodos austeníticos. Nesta condição, a velocidade de fusão não é aparentemente afetada pela polaridade. Na soldagem molhada, e particularmente para o eletrodo de aço carbono, a velocidade de fusão tende a ser menor com o eletrodo positivo. Além disto, a velocidade de fusão dos eletrodos austeníticos é reduzida, tornando-se praticamente igual à do eletrodo E6013.

Tabela 6. Velocidade de fusão dos diferentes eletrodos na soldagem a seco e malhada a 0,5 m.

\begin{tabular}{|c|c|c|c|c|c|}
\hline \multirow{2}{*}{ Ambiente } & \multirow{2}{*}{ Eletrodo } & \multirow{2}{*}{ Polaridade } & \multicolumn{2}{|c|}{ Vel. de fusão (mm/s) } & \multirow{2}{*}{$\begin{array}{l}\text { Efeito da polaridade } \\
\qquad(\mathrm{mm} / \mathrm{s})\end{array}$} \\
\hline & & & Média & Desvio & \\
\hline \multirow[t]{8}{*}{ Seco } & E6013 & $\mathrm{CC}+$ & 4,6 & 0,4 & 0,1 \\
\hline & & CC- & 4,5 & 0,0 & \\
\hline & $309 \mathrm{~L}$ & $\mathrm{CC}+$ & 5,7 & 0,6 & $-0,1$ \\
\hline & & CC- & 5,8 & 0,1 & \\
\hline & $312 \mathrm{~L}$ & $\mathrm{CC}+$ & 5,4 & 0,2 & 0,0 \\
\hline & & CC- & 5,4 & 0,4 & \\
\hline & $316 \mathrm{~L}$ & $\mathrm{CC}+$ & 6,1 & 0,2 & $-0,2$ \\
\hline & & CC- & 6,3 & 0,1 & \\
\hline \multirow[t]{8}{*}{ Molhado $(0,5 \mathrm{~m})$} & E6013 & $\mathrm{CC}+$ & 4,0 & 0,1 & $-1,0$ \\
\hline & & CC- & 5,1 & 0,4 & \\
\hline & $309 \mathrm{~L}$ & $\mathrm{CC}+$ & 4,7 & 0,4 & $-0,4$ \\
\hline & & CC- & 5,1 & 0,4 & \\
\hline & $312 \mathrm{~L}$ & $\mathrm{CC}+$ & 4,4 & 0,1 & $-0,2$ \\
\hline & & CC- & 4,6 & 0,1 & \\
\hline & $316 \mathrm{~L}$ & $\mathrm{CC}+$ & 4,8 & 0,0 & $-0,1$ \\
\hline & & CC- & 4,9 & 0,2 & \\
\hline
\end{tabular}

De forma similar a outros processos de soldagem a arco com eletrodo consumível, a fusão do eletrodo é controlada principalmente pelos aquecimentos pelo arco e por efeito Joule, embora, na soldagem com eletrodos revestidos, possam ainda existir contribuições significativas de reações endo ou exotérmicas de componentes do revestimento [12]. Diferentemente, contudo, da soldagem com alimentação contínua do eletrodo, na soldagem com eletrodo revestidos, a contribuição do aquecimento por efeito Joule varia durante o processo à medida que o eletrodo é consumido (o que tende a reduzir a resistência elétrica) e se aquece (o que aumenta a sua resistividade).

Tomando-se a resistência elétrica média do processo durante os curto-circuito como uma estimativa da resistência do eletrodo, observa-se, na soldagem ao ar, que a resistência dos eletrodos austeníticos tende a ser maior que a do eletrodo de aço carbono e não depender da polaridade (Tabelas 1 e 2). Como um comportamento similar foi observado na soldagem molhada, a redução na velocidade de fusão dos eletrodos austeníticos e o efeito da polaridade na soldagem molhada a $0,5 \mathrm{~m}$ devem estar relacionados principalmente com alterações no arco elétrico. Possivelmente, as perdas de energia para a água reduziram a transferência de calor do arco para o eletrodo apesar do aumento da tensão na soldagem em lâmina d'água.

Na Figura 11 pode-se observar a evolução da resistência de curto-circuito durante a soldagem a diferentes profundidades na soldagem com o eletrodo de aço carbono e com um dos eletrodos inoxidáveis ligados ao polo negativo. Nos gráficos, a evolução da resistência é caracterizada em termos de um "comprimento (ou tempo) relativo consumido" do eletrodo definido como a porcentagem do intervalo de medição (Figura 1). Além disto, para reduzir a dispersão dos resultados e a influência de curtos-circuitos de pequena duração, que tendem a apresentar maior resistência elétrica [14], cada ponto mostrado representa a média dos valores medidos em sete curtos-circuitos consecutivos. A Figura 11 não apresenta os resultados dos testes feitos em lâmina d'água, pois estes apresentaram menor quantidade de curtos circuitos e estes foram principalmente de curta duração. 


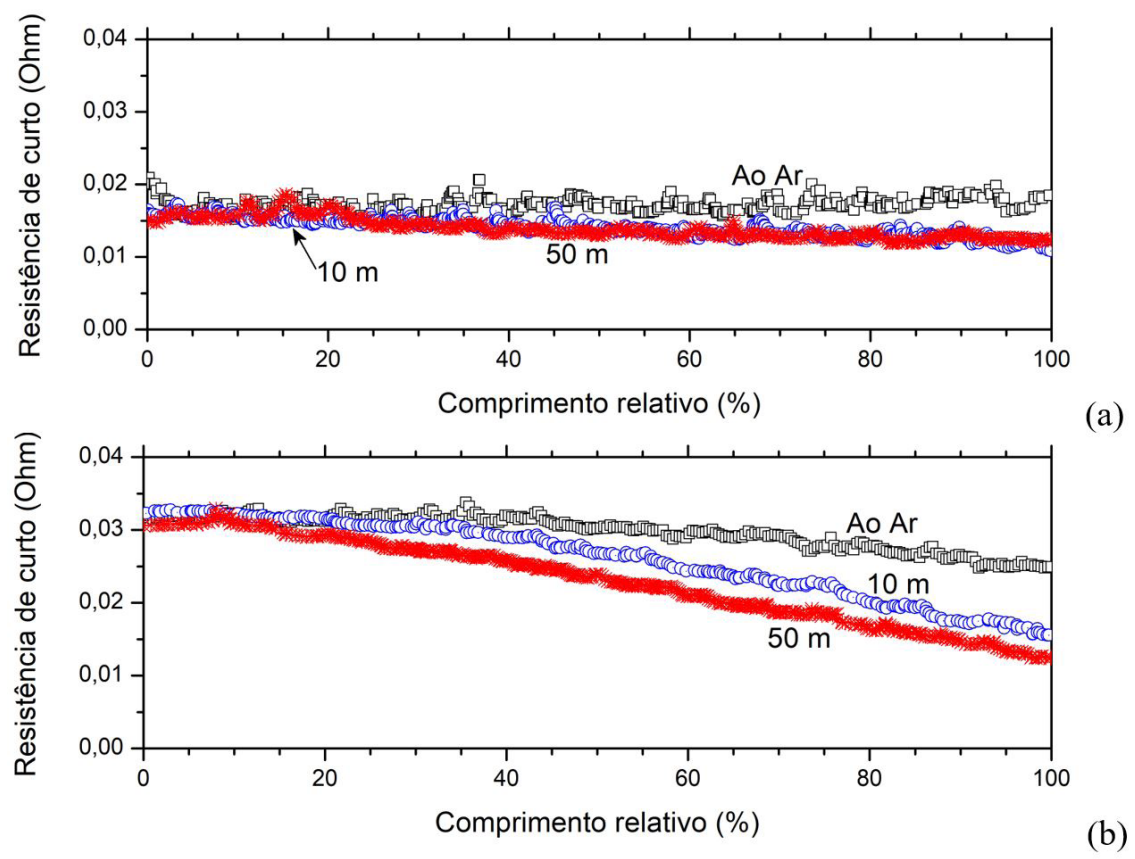

Figura 11. Evolução da resistência elétrica média durante curtos-circuitos com o comprimento relativo consumido do eletrodo: (a) E6013 e (b) E312L.

Observa-se que a resistência elétrica tende a cair à medida que o eletrodo é consumido, mas o efeito é mais evidente na soldagem com o eletrodo austenítico e nas maiores profundidades. Esta diminuição resulta de uma influência mais forte da redução do comprimento do eletrodo em comparação com o seu aquecimento na determinação de sua resistência elétrica durante a soldagem. A queda mais evidente na soldagem subaquática deve estar ligada a uma maior perda de calor pelo eletrodo devido ao seu contato com a água e este efeito deve se tornar mais importante com o aumento da profundidade. Finalmente, o efeito da redução de resistência elétrica com o consumo do eletrodo é mais evidente com o eletrodo austenítico, mesmo na soldagem ao ar, possivelmente devido ao menor efeito da temperatura sobre a resistividade elétrica deste aço. Estas alterações, menos evidentes na soldagem ao ar (e em lâmina d'água), podem ser relevantes para a evolução da velocidade de fusão de eletrodos revestidos, particularmente, para os de aço inoxidável austenítico, na soldagem molhada em maiores profundidades.

\section{Conclusões}

No presente trabalho foram estudadas as características operacionais de eletrodos revestidos de aço inoxidável austenítico na soldagem molhada em várias profundidades e os resultados comparados com a soldagem a seco e com eletrodo de aço carbono. As suas principais conclusões foram:

- Os eletrodos operaram com transferência globular e por curto-circuito e a quantidade de curtos-circuitos variou com a polaridade, ambiente e profundidade. A soldagem com o eletrodo de aço carbono apresentou maior quantidade de curtos-circuitos na soldagem ao ar enquanto que, com os eletrodos inoxidáveis, estes foram mais frequente a $50 \mathrm{~m}$, particularmente com polaridade negativa;

- Não se observou uma boa correlação entre valores de índices para inferir a estabilidade da soldagem e os resultados observados qualitativamente durante os testes. Por outro lado, a avaliação da evolução destes índices durante o processo apresenta potencial para identificar o desenvolvimento de instabilidades;

- Os eletrodos inoxidáveis tenderam a apresentar menor estabilidade na soldagem molhada, particularmente para a profundidade de $50 \mathrm{~m}$; 
- Na soldagem ao ar, a velocidade de fusão dos eletrodos inoxidáveis é maior do que a do eletrodo de aço carbono e não foi afetada pela polaridade. Na soldagem molhada, a operação com eletrodo negativo favoreceu uma maior velocidade de fusão. Nesta condição, a diferença na velocidade de fusão dos eletrodos inoxidáveis para o eletrodo de aço carbono tendeu a diminuir.

\section{Agradecimentos}

Os autores agradecem ao Laboratório de Robótica, Soldagem e Simulação (LRSS) da UFMG onde foram executados todos os testes de soldagem, a Esab pelo fornecimento dos eletrodos revestidos, a Usiminas pela doação do aço A36 e CAPES, CNPq e FAPEMIG pelo auxílio financeiro.

\section{Referências}

[1] Gao W-B, Wang D-P, Cheng F-J, Deng C-Y, Xu W. Underwater wet welding for HSLA steels: chemical, composition, defects, microstructures, and mechanical properties. Acta Metallurgica Sinica. 2015;23:1097-1108. http://dx.doi.org/10.1007/s40195015-0300-2.

[2] Ramchander J. Ultimate underwater welding technology in marine applications. International Journal Innovative Research in Science \& Engineering. 2016;9:175-185.

[3] Bai Q, Zou Y, Kong X, Gao Y, Dong S, Zhang W. The influence of the corrosion product layer generated on the high strength low-alloy steels welded by underwater wet welding with stainless steel electrodes in seawater. Journal of Ocean University of China. 2017;16(1):49-56. http://dx.doi.org/10.1007/s11802017-3057-6.

[4] Oliveira FR, Soares WR, Bracarense AQ. Estudo sobre o correlacionamento do fenômeno das bolhas e sinais elétricos na soldagem subaquática molhada com eletrodos revestidos. Soldagem e Inspeção. 2013;18(2):92-101. http://dx.doi. org/10.1590/S0104-92242013000200002.

[5] Feng J, Wang J, Sun Q, Zhao H, Wu L, Xu P. Investigation on dynamic behaviors of bubble evolution in underwater wet flux-cored arc welding. Journal of Manufacturing Processes. 2017;28:156-167. http://dx.doi.org/10.1016/j.jmapro.2017.06.003.

[6] Guo N, Fu Y, Wang Y, Du Y, Feng J, Deng Z. Effects of welding velocity on metal transfer mode and weld morphology in underwater flux-cored wire welding. Journal of Materials Processing Technology. 2017;239:103-112. http://dx.doi. org/10.1016/j.jmatprotec.2016.08.019.
[7] Khan MI, Ansari YA, Alam S. Comparative study of the response of commercially available electrodes to underwater-welding and air-welding. International Journal of Technical Research and Applications. 2015;3:413-419.

[8] Mazzaferro J A E, Machado IG. Study of arc stability in underwater shielded metal arc welding at shallow depths. Journal of Mechanical Engineering Science. 2009;223(3):699-709. http:// dx.doi.org/10.1243/09544062JMES1067.

[9] Liu S, Guerrero FP. Analysis of the arc signals acquired during wet welding. Golden: Colorado School of Mines; 2004. p. 28.

[10] Kakhovskyi Y, Kakhovskyi M. Development of welding consumables for wet underwater welding of high-alloy corrosion-resistent steel. Ukrainian Journal of Mechanical Engineering and Materials Science. 2015;1(1):83-89.

[11] Modenesi PJ, Avelar RC. The influence of small variations of wire characteristics on gas metal arc welding process stability. Journal of Materials Processing Technology. 1999;86(1-3):226232. http://dx.doi.org/10.1016/S0924-0136(98)00315-X.

[12] Quinn PT, Bracarense AQ, Liu S. A melting rate and temperature distribution model for shielded metal arc welding electrodes. Welding Journal. 1997;76(12):532s-538s.

[13] Omajene JE, Martikainen J, Kah P, Pirinen M. Fundamental difficulties associated with underwater wet welding. Journal of Engineering Research and Applications. 2014;4(6):26-31.

[14] Modenesi PJ, Costa MCMS, Santana IJ, Berganholi JPP. Estudo de alguns parâmetros básicos da soldagem GMAW com transferência por curto-circuito. Soldagem e Inspeção. 2011;16(1):12-21. http://dx.doi.org/10.1590/S0104-92242011000100003. 